\title{
Progress and Prospects of Non-literary Translation Teaching and Research in China*
}

\author{
Wenpeng Lü \\ College of Foreign Language and Literature, Northwest Normal University, Lanzhou, China \\ Email: 1vwpnwnu@163.com \\ Jing Wang \\ College of Foreign Language and Literature, Northwest Normal University, Lanzhou, China \\ Email: Wangjing0229@21cn.com
}

\begin{abstract}
The authors look to the future of teaching and research on non-literary translation in China by describing its current progress. The Chinese government has attached great importance to the problem, which shows that the postgraduate education of translation direction has been shifted from the academic type to the application one. Since the Chinese Economic Reform the research scope has been greatly widened, and consequently non-literary translation theories with Chinese characteristics have been developed. Now official discussion should be made to construct educational and theoretical systems of non-literary translation.
\end{abstract}

Index Terms — non-literary translation in China, teaching and research, progress and prospects

\section{INTRODUCTION}

From the perspective of stylistics, translation can be divided into literary translation and non-literary translation. Literary translation, which contains much artistic components, focuses on people's thinking and language, while non-literary translation, which contains much scientific elements, stresses realistic world ( $\mathrm{Li}$, 2009). Non-literary translation is widely used and almost consists of all translation activities except literary translation. Also known as pragmatic translation, applied translation or documentary translation, it is can be classified into professional translation and academic translation. Professional translation includes many aspects such as translation for foreign affairs (including diplomatic translation), news translation, economic and trade translation, business translation and tourism translation. Academic translation can be subdivided into general academic translation (such as academic writing, critical review of literature, academic discussion and academic reports) and professional academic translation (such as medical translation, engineering translation, financial translation and law translation). Most of the non-literary discourse possesses the informational, persuasive and anonymous characteristics (Fang, 2003). Various translation strategies are adopted according to different textual characteristics and translation requirements of the clients.

The translation activities in the world are mainly non-literary. Eugene Nida, American translation theorist, found that the proportion of literary translation in the all translation activities was less than 5\% (Wang, 2009). At present, 90\% of the translators are engaging in the non-literary translation activity (such as the translation of law books, diplomatic documents, scientific papers and business texts) and the proportion of literary translation in all the translation activities is less than $10 \%$. Against such a background, people in all walks of life begin to appeal for redefining "translation masters" and believe that the field of non-literary also needs masters. Presently, Chinese non-literary translation shows the characteristics of specialization, informationization and networking. The criterion of measuring whether non-literary translators are qualified and excellent depends on whether the translators are conforming to the norms of the occupation Compared with literary translation, current Chinese non-literary translation has the following characteristics: first, the proportion of scientific translation is declining while that of other non-literary translation is rising; second, the degree of commercialization has deepened and the trend of industrialization is getting obvious day by day; last, the forms of translation vary and translation aids equipments are widely used (Han, 2005). Different from literary translation, non-literary translation puts emphasis on information. Generally speaking, as long as the contents of the original texts of the non-literary translation can be accurately conveyed, it will be acceptable. Therefore, translators often adopt variation translation means such as rewriting, abstract translation and adaptation, or communicative translation. Assistant means used by the translators include parallel texts, e-tools and machine translation. Great progress has been made by Chinese researchers on non-literary translation. The present authors look to the future of teaching and research on non-literary translation in China by describing its current progress.

\footnotetext{
* Research supported by the "the Project of 'Eleventh Five-Year Plan' of Education Science in Gansu Province" (GSBG[2009]GX063) and the "Core Project for Enhancing the Research Capability of Young Teachers in Northwest Normal University (Humanities and Social Science)" (SKQNGG10014),
} 


\section{ThE PROGRESS AND PROSPECTS OF TEACHING ON NON-LITERARY TRANSLATION}

The descriptive analysis (TABLE 1) of the curriculum structure of undergraduate translation major (or direction) offered by 14 institutes and departments of colleges and universities in China indicates that the situation of curriculum design concerning the courses of non-literary translation (or applied translation courses) in these institutes and colleges is imbalanced. 6 of the 14 institutes and departments offer non-literary courses; only 1 one the 14 offers 16 courses (College 8); 5 of the 14 offer 1, 2 or 3 non-literary courses; the institutes which have courses from zero to three account for 11/14 in the total courses (78.57\%). Professors Jiang Qiuxia and Cao Jin (2006) believe that applied translation courses are few and that presently in the curriculum system of translation major (or direction), the cultivation of learners' ability in translation practice and application are lacking.

TABLE 1

STATISTICS OF APPLIED TRANSLATION COURSES FOR UNDERGRADUATE TRANSLATION MAJOR (OR DIRECTION) OFFERED BY 14 INSTITUTES AND DEPARTMENTS IN CHINA (JIANG \& CAO, 2006, P.9)

\begin{tabular}{|c|c|c|c|c|c|c|c|c|c|c|c|c|c|c|}
\hline College No. & 1 & 2 & 3 & 4 & 5 & 6 & 7 & 8 & 9 & 10 & 11 & 12 & 13 & 14 \\
\hline $\begin{array}{l}\text { Applied Translation* } \\
\text { (Quantity of the courses) }\end{array}$ & 5 & 0 & 0 & 3 & 1 & 0 & 3 & 16 & 1 & 1 & 0 & 0 & 7 & 0 \\
\hline
\end{tabular}

Authoritative survey indicates that the number of Chinese current translators and interpreters can not meet the needs of markets, and that although the shortage of competent translators and interpreters are obvious, the specialization and application of the translation are not paid much attention to $(\mathrm{Li}, 2007)$. The translation from Chinese into foreign languages (mainly from Chinese into English) is related to Chinese image. Thus from the perspective of foreign publicity, the shortage of competent translators and interpreters and low quality of translation have negative effect on Chinese national image. What is pleasant is that Chinese government has attached great importance to the non-literary translation and its teaching. Ministry of Education has officially approved Fudan University, Guangdong University of Foreign Studies \& Trades and Hebei Normal University as experimental schools to set up translation undergraduate major in 2006. By the time of September 2010, 31 universities have been approved by Ministry of Education to set up translation undergraduate major, which is a milestone in the Chinese translation discipline construction and its development. In addition, the State Council Academic Degree Office has formally approved the establishment of "Master of Translation and Interpreting (MTI thereafter)", aiming at cultivating the high-level, application-oriented and professional translators and interpreters. 15 universities (including Peking University and Fudan University) carried out the first experimental enrollment in 2008. By the end of January 2011, the total number of experimental universities is up to 158 , indicating that the Chinese postgraduate education of translation direction has been shifted from the academic type to the applied one.

Both the establishment of undergraduate translation major and the increase of the educational bases number for MTI aim at cultivating applied translators instead of training talents only mastering pure translation theories. It is worthwhile to notice that some universities concerned has met the new period of cultivating applied translators in the environment of the original academic type, and pure literature and linguistics ones. These universities and their faculties are facing the problems of changing concepts for cultivating translators and innovating curriculum. According to what the authors have observed, so far we have not caught up with the change of the situation in general, especially in the aspects of the curriculum setting, textbook compilation, the arrangement and adjustment of the qualified teaching staff, which are more or less lagging behind or are not adapted. Qualified teaching staff and textbooks are the current bottlenecks for non-literary translation teaching (He, 2010). It is necessary to supply, recruit and absorb experienced professional translators or interpreters outside the universities as part-time translation teachers. The textbook problem, which is complicated, not only involves the whole country but different regions and subject areas, so a special discussion on it is needed.

The demand for and cultivation to the applied translators call for the non-literary translation teaching and research keeping pace with the times. All colleagues should work together to implement this task. On the basis of consensus, we should set out to our task from the following aspects. Firstly, active publicity of the importance and urgency of non-literary translation teaching should be made. In the newly-set translation major (including MTI), it should be stressed that translation education should be in line with nation's each policy and the need for translators or interpreters in every field. It is necessary to make more people including relevant leaders understand that knowing foreign language is unequal to doing the translation and that general translation teaching in universities can not be equated to pragmatic translation, which is needed by the society. Secondly, our colleagues should continue to create the atmosphere on the teaching and research of non-literary translation. The stable contact system should be established among different regions and universities in our country so as to communicate each other and realize the complementary advantages. In recent years, the regular "National Seminar in Applied Translation" is an influential national platform, which should be further strengthened and expanded. Thirdly, new evaluation system of non-literary translation products should be formulated because the existing evaluation system takes "academe" as the standard or direction, which in fact has negative effect and can not objectively reflect the real progress and need of the teaching and research on non-literary translation. In the research area of non-literary translation, slogans of "simultaneous development of theory and 
practice" and "technique is more important than academe" should be advocated and researchers should be encouraged to write personal, thoughtful and practical papers. Lastly, a special journal for non-literary translation teaching and research should be started declaring that only papers concerning the "technique" of non-literary translation (or pragmatic translation) can be published rather than those about the "academe".

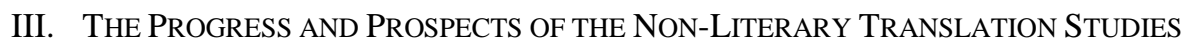

The achievements of the non-literary translation studies at home and abroad are represented by German Functionalism (Zeng, 2008). Functionalism describes and explains the translation activities mainly from the perspective of text typology and its functions and the Skopos of the translational action (Nord, 2001). In 1977, Katharina Reiss describes and explains the translation of the textual function from the perspective of text types (classified based on the communicative functions such as conveyance, expression and causativeness) and discourse genre or discourse variation. In 1978, Hans Vermeer came up with Skopostheorie and its related conceptual terms such as goals, intentions and function. In 1981, the Theory of Translation Action developed by Justa Holz Manttari put special emphasis on the actional aspects of the translation process, comprehensively analyzing the roles of the participants and the situational conditions. In 2001, Christiane Nord created the function-plus-loyalty model and distinguished the documentary translation and the instrumental one. Although German functionalists could explain the non-literary translation to some extent, the limitations still exist in theory.

In China the research scope of non-literary translation has been greatly widened since the reform and opening up. Scientific translation studies gain great development first followed by the translation studies on the business, tourism and news. With the new century coming, studies on law translation and the translation of public signs have become hotspots. Professor Lin Kenan (2008) introduced the situation of China's theoretic development in non-literary translation in the past decade based on his personal experiences of participating translation activities of World Table Tennis Championships in Tianjin and the Beijing Olympic Games.

Since the 43rd World Table Tennis Championships held in Tianjin in 1995, non-literary translation began to rise while the development of non-literary translation theory was correspondingly slow. At that time, Nida's dynamic equivalence translation theory was widely cited in both literary and non-literary translation studies. Professor Lin Kenan used Nida's translation theory in the process of his translation and deeply felt it did fully play the guiding role in the practical translation. When it was time to translate documents of the 2008 Beijing Olympic Games, the situation has changed a lot compared with that ten years ago. Non-literary translation has greatly increased in the quantity and its theory has gained great development correspondingly. China has introduced a large number of foreign translation theories, especially the Skopostheorie, the cultural turn theory and the text typology. Meanwhile, on the one hand, some Chinese scholars absorbed foreign translation theories; on the other hand, they tried to establish Chinese non-literary translation theories by combining foreign theories and China's translation practice. These scholars include Huang Youyi (2004)'s three close principles on the foreign publicity translation, Li Xin (2003)'s pre-translation processing theory, , Lin Kenan etc. (2003)'s seeing, translating and writing theory, Ding Hengqi (2006)'s A-B-C model (imitation-borrowing-creating). Compared with foreign non-literary translation theories, theories developed by Chinese scholars are more practical. In the course of translating the documents on Beijing Olympic Games, Professor Lin fully made use of Chinese translation theories to guide the translation practice, overcoming many difficulties, solving cognitive problems which could not have been solved with traditional translation theories, finishing the translation task smoothly and passing the acceptance check of the Olympic Games Organizing Committee.

China's non-literary translation studies over the past decade can be divided into three categories: the exploration of translation theories, language features and techniques of translation, and translation criticism (Chen, 2010). In the aspect of translation theories, the exploration of translation principles and standards are the domain part, and studies concerning culture and translation, linguistic theory and translation, and interdisciplinary studies should be improved. More than $60 \%$ of non-literary translation studies belong to discussions on language features and translation techniques, and in most of these discussions, words, sentences and discourse of only one text are analyzed. Quantitative and systematic studies of linguistic features of non-literary translation based on corpus are far from enough. Translation criticism should be enhanced in both quality and quantity although there are many discussions and comments on mistranslation.

The authors believe that the future research in non-literary translation field should pay sufficient attention to interdisciplinary studies, corpus-based and machine translation studies and studies concerning non-literary translation from Chinese to foreign languages reflecting the cultural characteristics of traditional Chinese style. Great importance should be attached to the interdisciplinary studies between non-literary translation and pragmatics, and corpus, and discourse studies, and cognitive science, and contrastive studies of languages and cultures. Relevant theories and special knowledge are involved in non-literary texts such as commerce and trade, law, finance and contracts. So it is difficult to make high-quality non-literary translation practice and research if translators are lack of necessary knowledge of related disciplines. Corpus-based non-literary translation, machine translation and the application of translation corpora lead scholars to raise the awareness that translation studies should transit from prescription to description. Compared with foreign countries, the future of China's corpus-based translation studies is not optimistic. A few translation corpora are under construction or have been completed, of which only two or three can be directly used in translation studies. 
Compared with economy and law translation studies, Chinese-English non-literary translation studies reflecting traditional Chinese culture are not sufficient, although Liu Fagong (1999), Lan Fengli (2003), Li Weibin (2004) and other scholars have studied the Chinese-English translation of Chinese recipes and Chinese medicine in-depth. Therefore, it is necessary to give priority to the translation studies of Chinese food, martial arts, Chinese medicine, architecture, drama, painting, tea, silk clothing, ceramics, folk art, ritual practices in the future.

\section{CONCLUSION}

China's modernization, reform and opening up are the original impetus to develop the teaching, practice and studies of non-literary translation. The translation teaching is continuously oriented to cultivating applied translators with the overall development of the translation studies as well as the impetus from the large amount of practice in non-literary translation. Now official discussion should be made to construct educational and theoretical systems of non-literary translation.

\section{REFERENCES}

[1] Chen, Jianping. (2010). Pragmatic Translation Studies in China: A Review and Prospects. Journal of Ningbo University (Liberal Arts Edition) 1, 40-45.

[2] Ding, Hengqi. (2006). Making Great Efforts to Improve Cities' Public Signs and Gradually Establishing Standard Translation. Chinese Translators Journal 27.6, 42-46.

[3] Fang, Mengzhi. (2010). Position and Academic Studies of the Applied Translation in China. Chinese Translators Journal 31.1, 47-49.

[4] Han, Ziman. (2005). Practice and Theoretical Studies of Applied Translation. Chinese Science \& Technology Translators Journal 18.4, 48-51, 61.

[5] He, Gangqiang. (2010). Practically Focusing on Application and Cultivating Qualified Translators. Shanghai Journal of Translators 1, 37-40.

[6] Huang, Youyi. (2004). Insisting on the "Three Close Principles" and Properly Dealing with the Difficult Problems in Foreign Publicity Translation. Chinese Translators Journal 25.6, 27-28.

[7] Jiang, Qiuxia \& Cao Jin. (2006). Analysis and Advice on the Situation of Translation Major's Construction. Chinese Translators Journal 27.5, 8-13.

[8] Lan, Fengli. (2003). On the Influence of Chinese Medicine Culture on the C-E Translation of Chinese Medicine. Chinese Translators Journal 24.4, 72-75.

[9] Li, Changshuan. (2009). Non-literary Translation. Beijing: Foreign Language Teaching and Research Press.

[10] Li, Jun, Baoyin Huang \& Rui Zhu. (2007). Reform and Improvement of the Postgraduates' Cultivating Model Majoring in Foreign Languages and Training Qualified Translators with MTI. Chinese Translators Journal 28. 4, 6-7.

[11] Li, Weibing. (2004). On the Basic Principles of C-E Chinese Medicine Translation from the Perspective of Cultural Difference Between Chinese and Westerners. Shanghai Journal of Translators for Science and Technology 4, 57-59.

[12] Li, Xin. (2001). Pre-Translation Processing in Foreign Publicity Translation. Shanghai Journal of Translators for Science and Technology 6, 18-22.

[13] Lin, Kenan. (2008). Translation from World Table Tennis Championships to Beijing Olympic Games. Chinese Translators Journal 29. 1, 57-60.

[14] Lin, Kenan \& Mingwen Ji. (2003). Pragmatic English Translation Appealing for the Guidance of Theory. Shanghai Journal of Translators for Science and Technology 3, 10-12.

[15] Liu, Fagong. (1999). C-E Translation of Commerce and Trade. Chongqing: Chongqing Publishing House.

[16] Nord, Christiane. (2001). Translation as a Purposeful Activity: Functionalist Approaches Explained. Shanghai: Shanghai Foreign Language Education Press.

[17] Wang, Yinquan. (2009). Non-literary Translation: Conceptual Remodeling of Translation Textbook Construction and Translation Teaching. Foreign Language World 2, 40-49.

[18] Zeng, Lisha. (2008). On the Domain-Expanding of Applied Translation Theory from the Perspective of Translation Theory Construction. Shanghai Journal of Translators 3, 1-5.

Wenpeng Lü was born in Gansu, China in 1966. She received her M.A. degree in linguistics from Northwest Normal University, China in 1999. She is currently an associate professor and M.A. supervisor at College of Foreign Language and Literature in Northwest Normal University, China. Her research interests include linguistics and translation studies.

Jing Wang was born in Gansu, China in 1984. She is a postgraduate admitted in 2009 by the College of Foreign Language and Literature in Northwest Normal University, China. Her research interest is translation studies. 